\title{
Article \\ Microstructure, Mechanical Properties, Degradation Behavior, and Implant Testing of Hot-Rolled Biodegradable ZKX500 Magnesium Alloy
}

\author{
Ying-Ting Huang ${ }^{1}$, Fei-Yi Hung ${ }^{1, * \mathbb{C}}$, Fa-Chuan Kuan ${ }^{2}$, Kai-Lan Hsu ${ }^{2}$, Wei-Ren $\mathrm{Su}^{2}$ and Chia-Yen Lin ${ }^{3}$ \\ 1 Department of Materials Science and Engineering, National Cheng Kung University, Tainan 701, Taiwan; \\ ffbvinkg@gmail.com \\ 2 Orthopaedic Department, College of Medicine, National Cheng Kung University, Tainan 701, Taiwan; \\ justoversea@hotmail.com (F.-C.K.); dulendulen@gmail.com (K.-L.H.); suwr@ms28.hinet.net (W.-R.S.) \\ 3 Ting Sin Co., Ltd., Tainan 701, Taiwan; lcy@ts-metal.com.tw \\ * Correspondence: fyhung@mail.ncku.edu.tw
}

check for

updates

Citation: Huang, Y.-T.; Hung, F.-Y.; Kuan, F.-C.; Hsu, K.-L.; Su, W.-R.; Lin, C.-Y. Microstructure, Mechanical Properties, Degradation Behavior, and Implant Testing of Hot-Rolled Biodegradable ZKX500 Magnesium Alloy. Appl. Sci. 2021, 11, 10677. https://doi.org/10.3390/ app112210677

Academic Editor: Cristina M. Cordas

Received: 16 September 2021

Accepted: 10 November 2021

Published: 12 November 2021

Publisher's Note: MDPI stays neutral with regard to jurisdictional claims in published maps and institutional affiliations.

Copyright: (c) 2021 by the authors. Licensee MDPI, Basel, Switzerland. This article is an open access article distributed under the terms and conditions of the Creative Commons Attribution (CC BY) license (https:/ / creativecommons.org/licenses/by/ $4.0 /)$.

\begin{abstract}
Currently, orthopedic metallic implants are mostly made of stainless steel and titanium alloys. After healing, patients are usually required to undergo a secondary surgery for implant removal, which not only poses a medical risk but also costs medical resources. Magnesium-based biodegradable implants that can be absorbed by humans promote osteoblastic activity during the degradation and inhibit the formation of osteoclasts. Moreover, magnesium can be detected by X-ray, and this can help doctors to perform postoperative diagnosis and treatment, which is beneficial for patients. In this study, a ZKX500 Mg alloy bone plate was prepared through rolling. In addition to the microstructure and the mechanical properties of the hot-rolled ZKX500 Mg alloy, its in vitro corrosion behavior under different heat treatment conditions is discussed. A 6-month mini-pig implantation test was conducted using the fabricated ZKX500 Mg alloy bone plate and bone screws. The in vivo degradation mechanism and new bone formation were observed using computed tomography images. The pig recovered well, and the results can serve as an important reference for clinical applications. In addition, another important contribution of this study is that it can help the field of orthopedics to better understand the biodegradable magnesium alloy.
\end{abstract}

Keywords: magnesium alloy; biodegradation; mechanical properties; animal experiment; bone plate

\section{Introduction}

Magnesium has a low density, merely $1.74 \mathrm{~g} / \mathrm{cm}^{3}$, and the material has a high strengthto-weight ratio, good damping capability, and recyclability. Owing to these attributes, magnesium is widely used in the automobile, aerospace, and electronics industries [1,2]. $\mathrm{Mg}$ alloy has excellent mechanical properties and an elastic modulus close to that of human bone [3], therefore, it is a promising material for use in the biomedical field. $\mathrm{Mg}$ has a hexagonal close packed (HCP) structure with scant slip systems, and its ductility and workability are poor compared with those of other metals, which limits its applications.

According to the literature on magnesium alloys, hot working can cause dynamic recrystallization of the material, resulting in grain refinement and improvement of mechanical properties [4]. Moreover, finer grains can change the corrosion behavior of the material from localized corrosion to general corrosion [5], which has positive benefits for biomedical applications. Furthermore, the twinning structure of the $\mathrm{Mg}$ matrix formed during hot rolling can improve the ductility of the material [6]. Notably, the structure formed due to hot working is unstable [7]. Therefore, annealing is required to reduce the residual stress and control the recrystallization mechanism of $\mathrm{Mg}$ matrix.

According to previous reports, the ZKX500 Mg-Zn-Zr alloy can be used to manufacture bone screws for the purpose of clinical applications [8,9]. However, few studies 
have investigated the use of $\mathrm{Mg}$ alloy bone plates. In this study, the mechanical properties and corrosion mechanism of hot-rolled and heat-treated ZKX500 Mg-Zn-Zr alloy plates were evaluated. Then, the $\mathrm{Mg}$ alloy plate with the superior process condition was selected and machined into a four-hole bone plate. Furthermore, a mini-pig implantation test was conducted for 6 months to explore the degradation and progress of bone growth inside the body. The relevant results can serve as a reference for use of the material in biomedical applications.

\section{Materials and Methods}

\subsection{Materials}

In this study, we used a ZKX500 Mg-Zn-Zr alloy (Ting Sin Co., Ltd., Tainan, Taiwan). The extruded material obtained from the cast $\mathrm{Mg}$ alloy ingot is denoted as $\mathrm{F}$. The specimen subjected to homogenization heat treatment at $380^{\circ} \mathrm{C}$ for $2 \mathrm{~h}$ is denoted $\mathrm{FH}$. The other specimens were cut from $\mathrm{F}$ for the rolling process. The hot-rolled process was performed at $300{ }^{\circ} \mathrm{C}$ for $30 \mathrm{~min}$, the reduction rate was $10 \%$ per pass, and the $\mathrm{Mg}$ plate was rolled from $6 \mathrm{~mm}$ to $3 \mathrm{~mm}$ in thickness, as illustrated in Figure 1. Then, specimens cut from the rolled plate were annealed at $380{ }^{\circ} \mathrm{C}$ for different durations ( $5 \mathrm{~min}, 10 \mathrm{~min}, 30 \mathrm{~min}$, and $60 \mathrm{~min}$ ) to reduce the residual stress induced by rolling; these specimens are denoted FRH05, FRH10, FRH30, and FRH60, respectively.

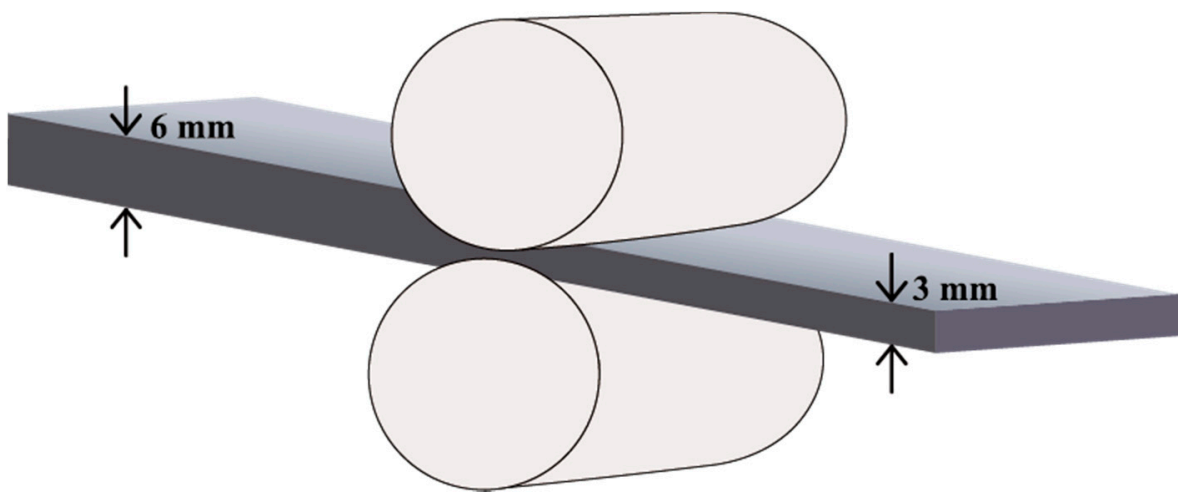

Figure 1. Rolling process: $\mathrm{Mg}$ plate was rolled from $6 \mathrm{~mm}$ to $3 \mathrm{~mm}$.

\subsection{Microstructure Characterization and Mechanical Properties}

The ZKX500 Mg-Zn-Zr specimens were ground with $\mathrm{SiC}$ sandpaper and polished with $\mathrm{Al}_{2} \mathrm{O}_{3}$ solution. Finally, they were etched with a mixture of $4.0 \mathrm{~g}$ of picric acid, $10 \mathrm{~mL}$ of acetic acid, and $90 \mathrm{~mL}$ of ethanol. An optical microscope (OLYMPUS BX41M-LED, Tokyo, Japan) was used to observe the microstructure of the specimens, and an X-ray diffraction (XRD) spectroscope (Bruker AXS GmbH, Karlsruhe, Germany) was used to analyze their phase structures [10]. A hardness test (Mitutoyo, Kawasaki-shi, Japan) was performed to measure the Rockwell hardness scale grade $\mathrm{F}$ (HRF) of the specimens. The size of the specimens used in the tensile test is depicted in Figure 2a. A tensile testing machine (Hung-Ta HT-8336, Taichung, Taiwan) was used to conduct the tensile test, and the tension rate was $1 \mathrm{~mm} / \mathrm{min}$. 
(a) Tensile test specimen

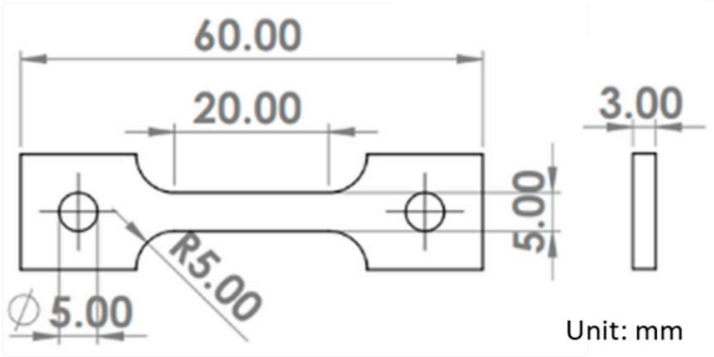

(b) Impact toughness test specimen

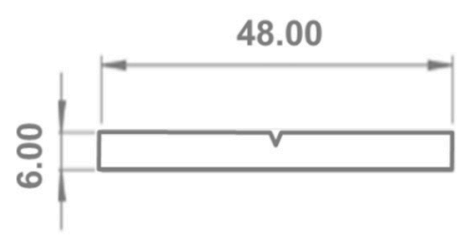

(c) Implant test specimen

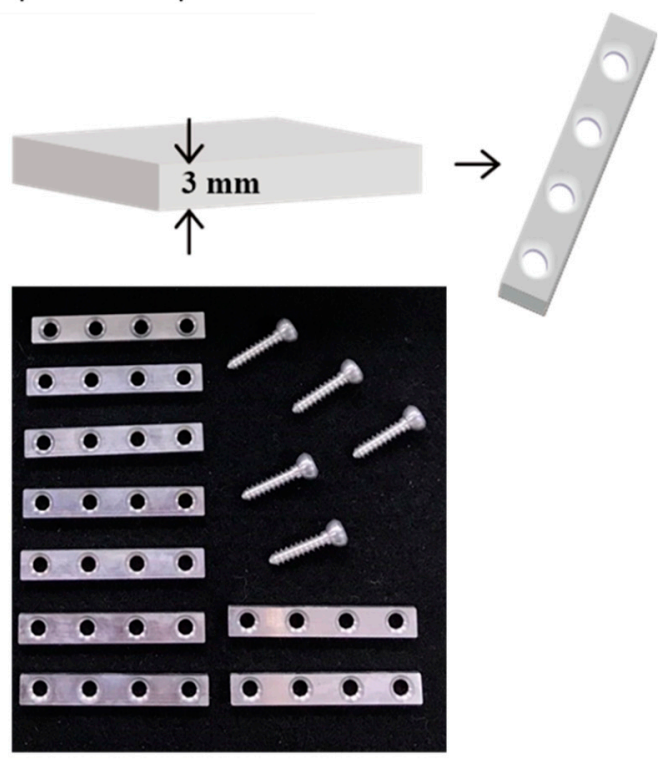

Figure 2. Geometry of test specimens: (a) tensile test, (b) impact toughness test, and (c) illustration and photograph of the ZKX500 bone plates.

\subsection{In Vitro Degradation Test}

In addition, according to ASTM G31-72 [11,12], an immersion test was conducted in 0.9 wt. $\% \mathrm{NaCl}$ solution at ambient temperature. The corrosion mechanism was evaluated with scanning electron microscopy (HITACHI SU-5000, HITACHI, Tokyo, Japan) and $X R D$ [13]. Notably, the elemental distributions were characterized by an electron probe micro analyzer (EPMA, JEOL JXA-8900R, Taipei, Taiwan). A Charpy impact test using an impact testing instrument was used to evaluate the impact toughness after the immersion test. The dimensions of the specimens are shown in Figure $2 b$.

\subsection{Cytotoxicity Assessments}

To test the biocompatibility of the ZKX500 Mg-Zn-Zr alloy, a cytotoxicity test was conducted by following the ISO 10993-5 standard [14] and using the MG63 cell line (CRL1427, ATCC, USA). The ZKX500 specimen after homogenization heat treatment was placed in Dulbecco's Modified Eagle Medium with $10 \%$ fetal bovine serum and extracted at $37^{\circ} \mathrm{C}$ in a humidified $5 \% \mathrm{CO}_{2}$ atmosphere for $24 \mathrm{~h}$. The ratio of the surface area of the specimen to the volume of the medium was $1.25 \mathrm{~cm}^{2} / \mathrm{mL}$ [15]. Cells were seeded with a density of 2000 cells/well in 96-well culture plate and incubated for $24 \mathrm{~h}$. Then, the medium was replaced with the extract, a negative control (only medium), or a positive control (medium with 5\% DMSO). After incubation for a specific number of days, CCK-8 solution was added, and the contents of the culture plate were incubated for an additional $2 \mathrm{~h}$ to ensure completion of the reaction between the medium and CCK-8. Then, the optical density (OD) of the medium was measured at the wavelength of $450 \mathrm{~nm}$ by using ELISA reader. The OD values were converted into the relative growth rate (RGR) by using the following equation:

$$
\operatorname{RGR}(\%)=\left(\frac{\mathrm{OD}_{\text {test }}-\mathrm{OD}_{\text {blank }}}{\mathrm{OD}_{\text {negative }}-\mathrm{OD}_{\text {blank }}}\right) \times 100 \%
$$

\subsection{In Vivo Implantation Experiment}

In addition, the ZKX500 specimen was then machined into a four-hole bone plate (Figure 2c) with four ZKX500 Mg screws for use in an animal experiment. Lanyu swine was the experimental animal in this study. The animal experiment adhered to protocol approved by the Institutional Animal Care and Use Committee (IACUC) of the preclinical 
testing facility (NARLabs, Tainan, Taiwan). The bone plate and the bone screws were implanted at the radius of right forelimb, and the operative location is depicted in Figure 3a. Observation was continued for 6 months, and computed tomography (CT) images were recorded to evaluate the degradation of the $\mathrm{Mg}$ alloy and bone growth.

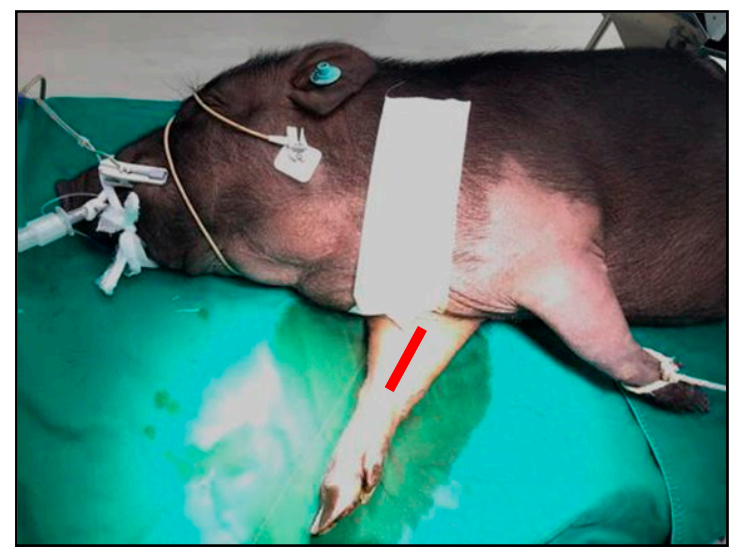

(a)

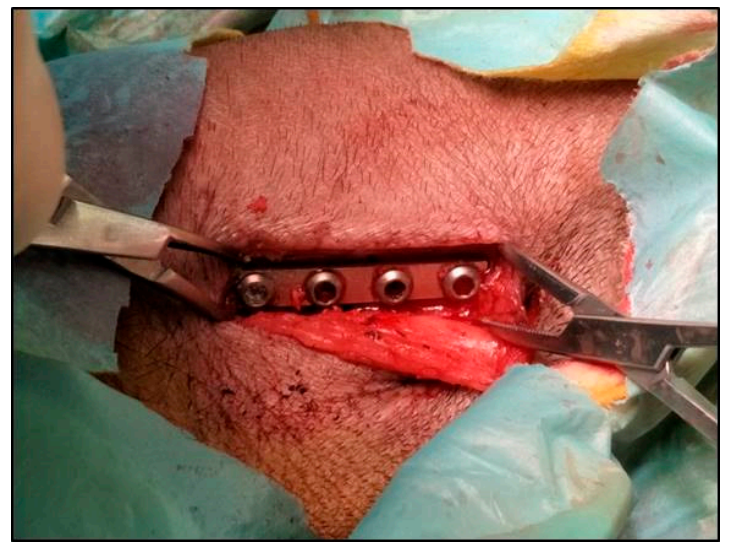

(c)

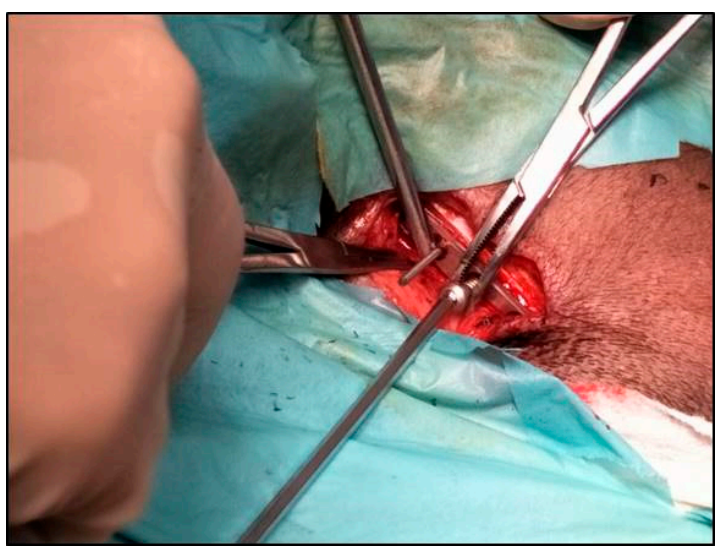

(b)

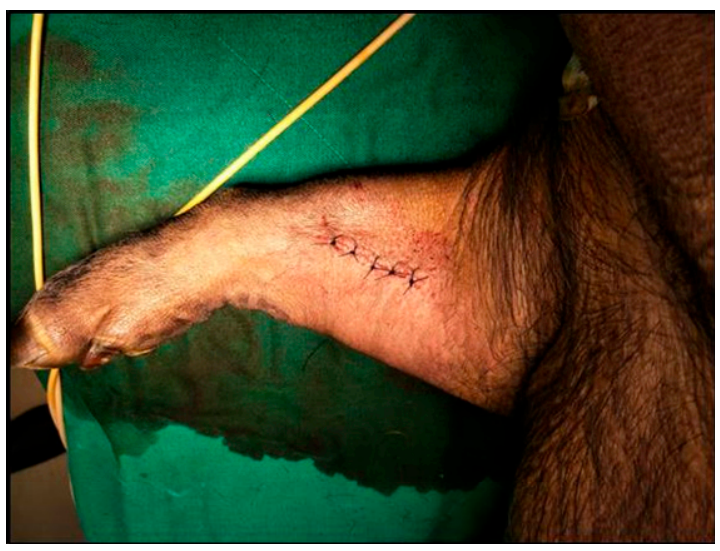

(d)

Figure 3. In vivo test of ZKX500 Mg bone plate and screws: (a) animal on the operation table with red line denoting the incision position, (b) insertion of a magnesium screw into the magnesium bone plate, (c) complete insertion of the screw, and (d) appearance of the animal after suturing of the wound.

The surgical procedure was conducted as follows: a 4-cm-long incision was made on the upper skin of the radius, using a $\mathrm{K}$ pin to position and expand the holes on the radius, as shown in Figure $3 \mathrm{~b}$. Then, the $\mathrm{Mg}$ plate was placed and locked in using the $\mathrm{Mg}$ bone screws, as illustrated in Figure 3c. Finally, the subcutaneous tissue and epidermis were sutured with $4 / 0$ absorbable thread and 2/0 nonabsorbable thread, respectively, as depicted in Figure 3d. After the experiment was completed, the pig was sacrificed following animal euthanasia procedures [16].

\section{Results and Discussion}

\subsection{Microstructure and Phase Analysis}

Figure $4 \mathrm{a}, \mathrm{b}$ shows the microstructures of the $\mathrm{F}$ and the $\mathrm{FH}$ specimens. In the $\mathrm{F}$ specimen, the matrix was composed of both coarse and fine grains. After homogenization heat treatment, the grain distribution became relatively uniform, and the average grain size was approximately $5 \mu \mathrm{m}$. By contrast, after the as-extruded material was hot-rolled, grain refinement and deformation twinning occurred, as depicted in Figure 4c, and as the annealing time increased, the grains tended to grow. 


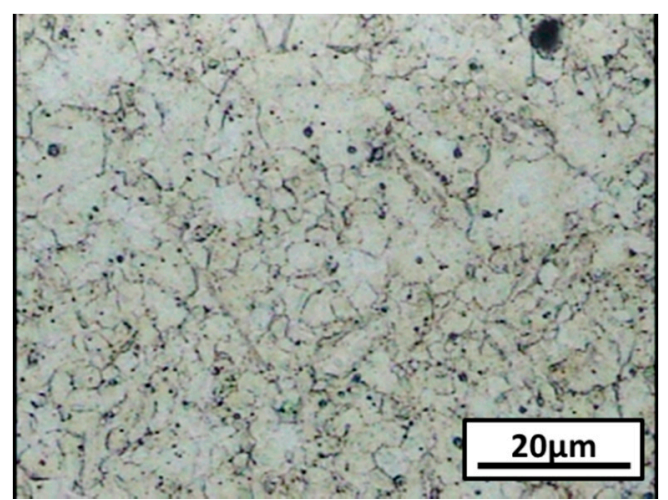

(a)

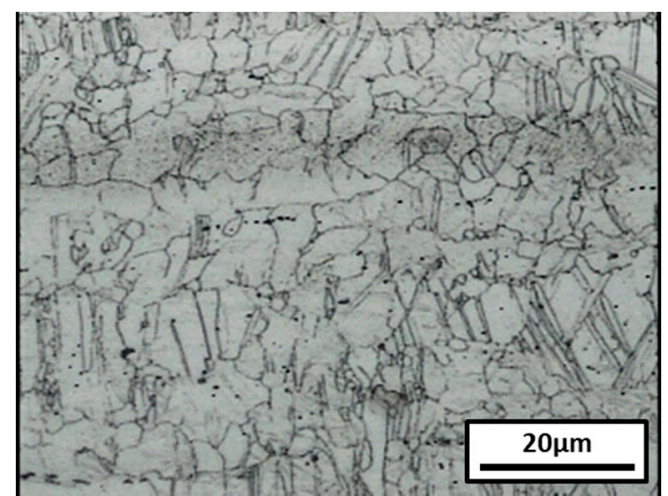

(c)

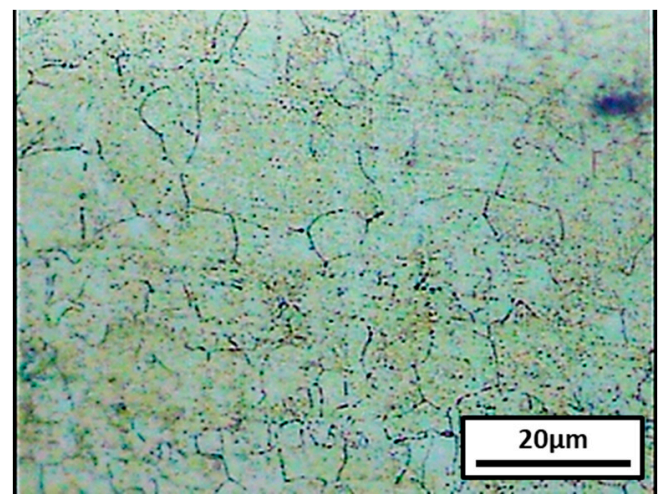

(e)

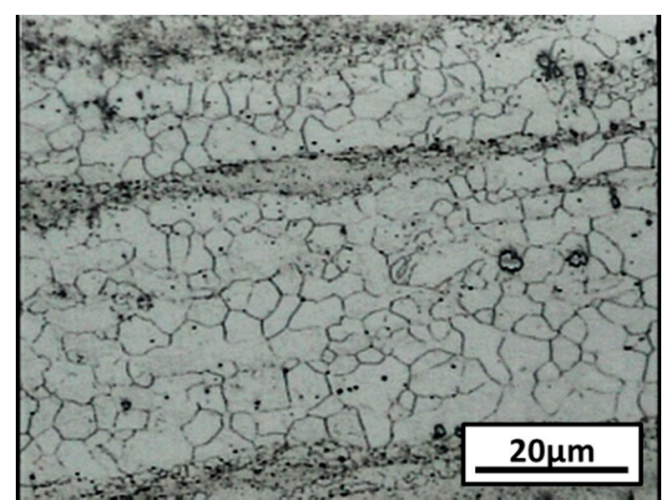

(b)

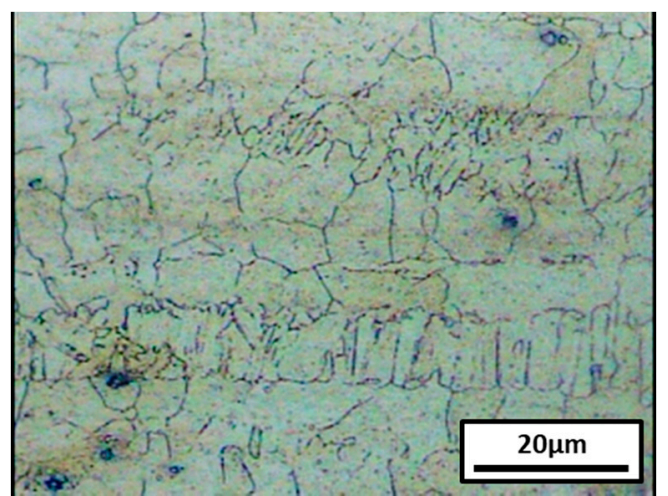

(d)

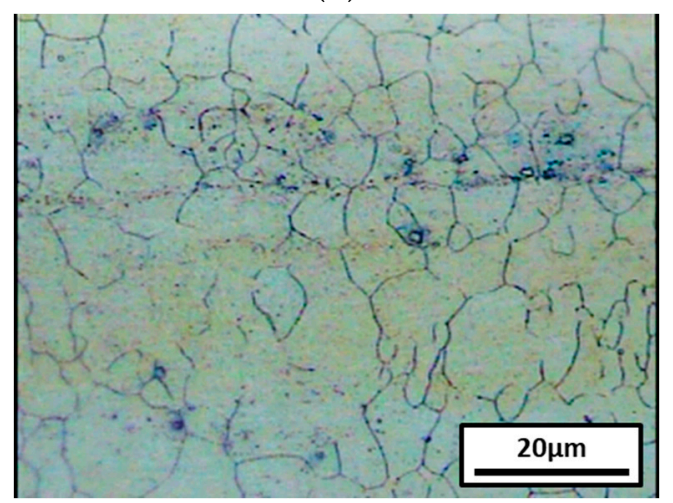

(f)

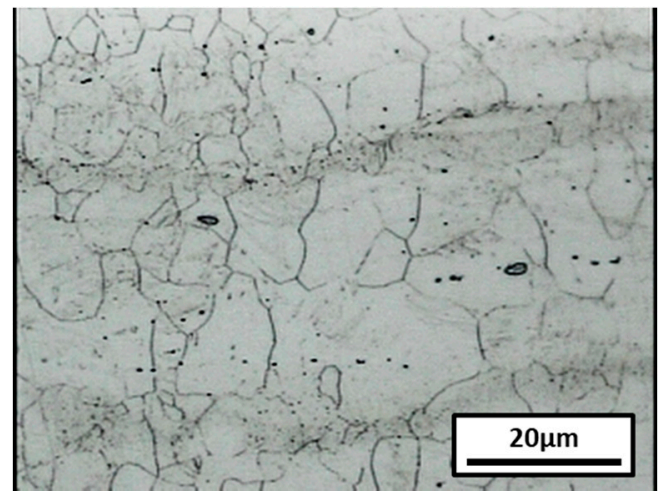

(g)

Figure 4. Microstructure of ZKX500 Mg alloy: (a) F, (b) FH, (c) FR, (d) FRH05, (e) FRH10, (f) FRH30, and (g) FRH60. 
Figure 5a shows the results of the XRD analysis of the $\mathrm{F}$ and $\mathrm{FH}$ specimens. The diffraction peaks represent mainly the $\alpha-\mathrm{Mg}$ phase and a few $\mathrm{MgZn}_{2}$ phases. Homogenization heat treatment caused the second phase to dissolve into the matrix, which reduced the magnitudes of the $\mathrm{MgZn}_{2}$ phase peaks; moreover, splitting of high-angle peaks can be observed as well. Figure $5 \mathrm{~b}$ shows the results of XRD analysis of the FR and FRH specimens. Mg alloys have the HCP structure during the rolling process, moving along the basal slip system; as a result, at approximately $30^{\circ}$, the $\mathrm{Mg}(0002)$ signal intensified [17]. The experimental results indicated that annealing can reduce not only the residual stress induced by rolling, but also cause grain growth. However, the rolling texture did not change significantly.

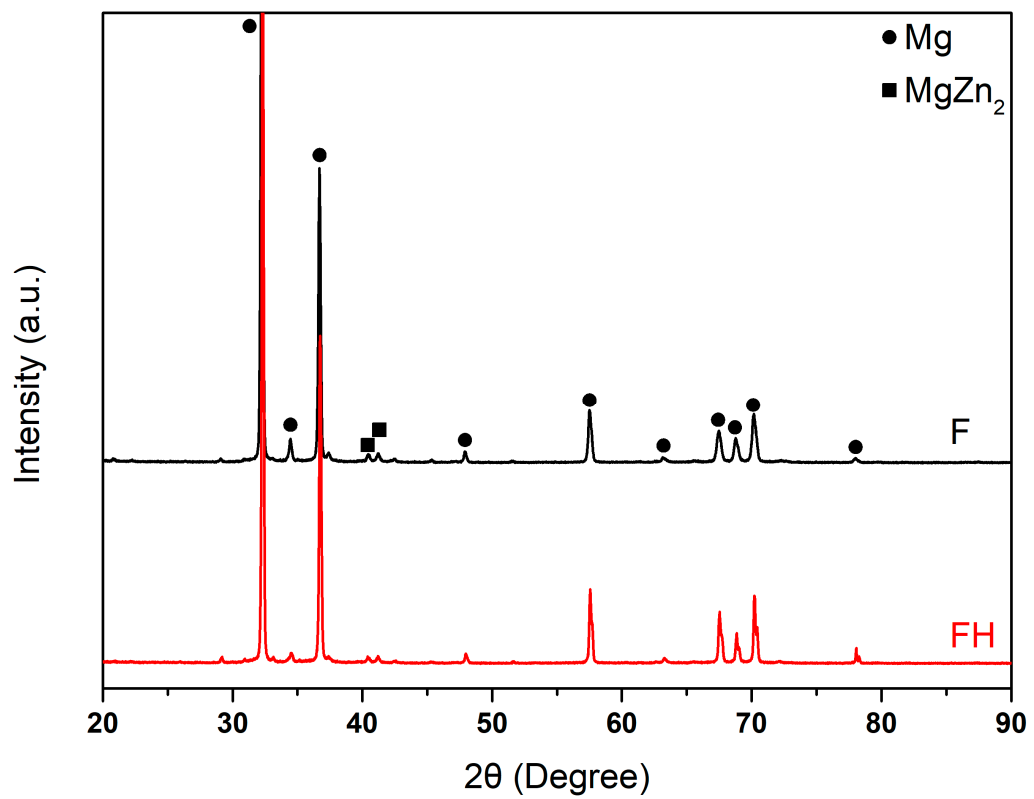

(a)

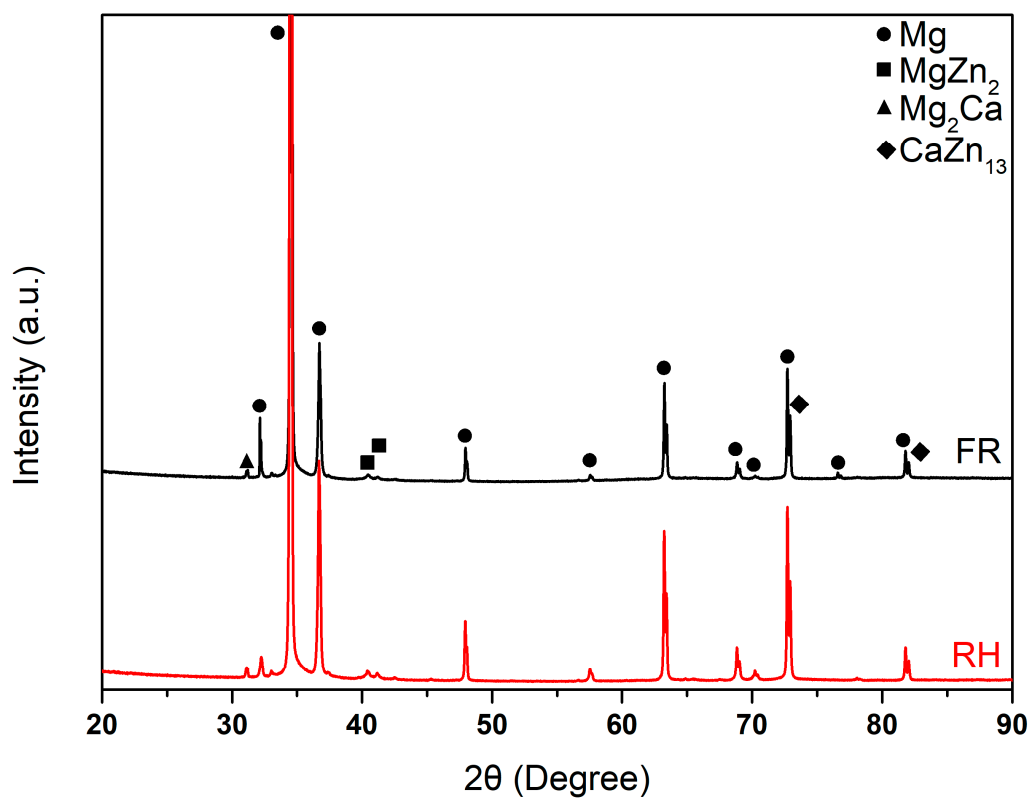

(b)

Figure 5. XRD patterns of ZKX500: (a) F and FH, and (b) FR and RH. 


\subsection{Hardness and Tensile Mechanical Properties}

Table 1 presents the hardness of all of the specimens. For the raw materials, hardness of the F specimen was approximately HRF 80 . After homogenization heat treatment, owing to dissolution of the second phases, the hardness of specimen decreased to HRF 77. Rolling can cause the dislocation strengthening, therefore, the hardness increased slightly to HRF 84 after rolling. As for the annealing after rolling, the hardness decreased as the annealing time was increased.

Table 1. Hardness of ZKX500 specimens.

\begin{tabular}{cccccccc}
\hline Hardness & F & FH & FR & FRH05 & FRH10 & FRH30 & FRH60 \\
\hline HRF & 80 & 77 & 84 & 78 & 75 & 76 & 74 \\
\hline
\end{tabular}

The residual stress in the F and FR specimens was reduced by annealing, and, as a result, the specimens were suitable for the fabrication of bone plates. Therefore, F and FR specimens were not included in the tensile test. Figure 6 presents the tensile mechanical properties of the specimens. The FH specimen had the highest ultimate tensile strength (approximately $307 \mathrm{MPa}$ ). After rolling and annealing, the tensile strengths of the specimens decreased due to recrystallization and grain growth. However, their ductility increased. To compare the results, we observed the fracture surfaces of the specimens after the tensile test. Figure 7 depicts the fracture surfaces of the FH and FRH30 specimens. In both specimens, the fracture surface exhibits a dimple structure, which is the characteristic of ductile fracture. Notably, the FH specimen had a more undulating surface with higher roughness, mainly due to the metal texture produced during extrusion. The FRH30 specimen had a fine structure after rolling, and, therefore, its fracture surface was smoother.

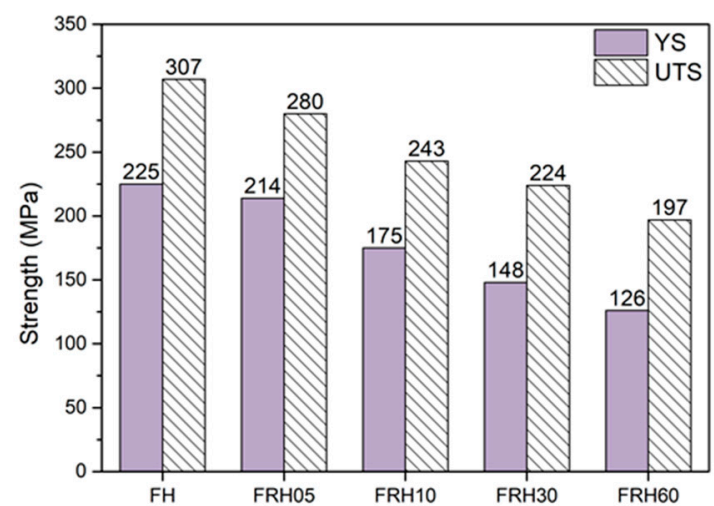

(a)

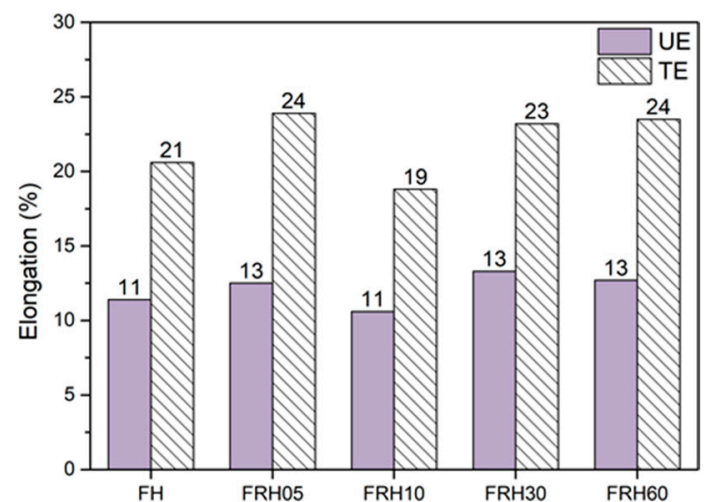

(b)

Figure 6. Mechanical properties of ZKX500: (a) strength and (b) elongation.
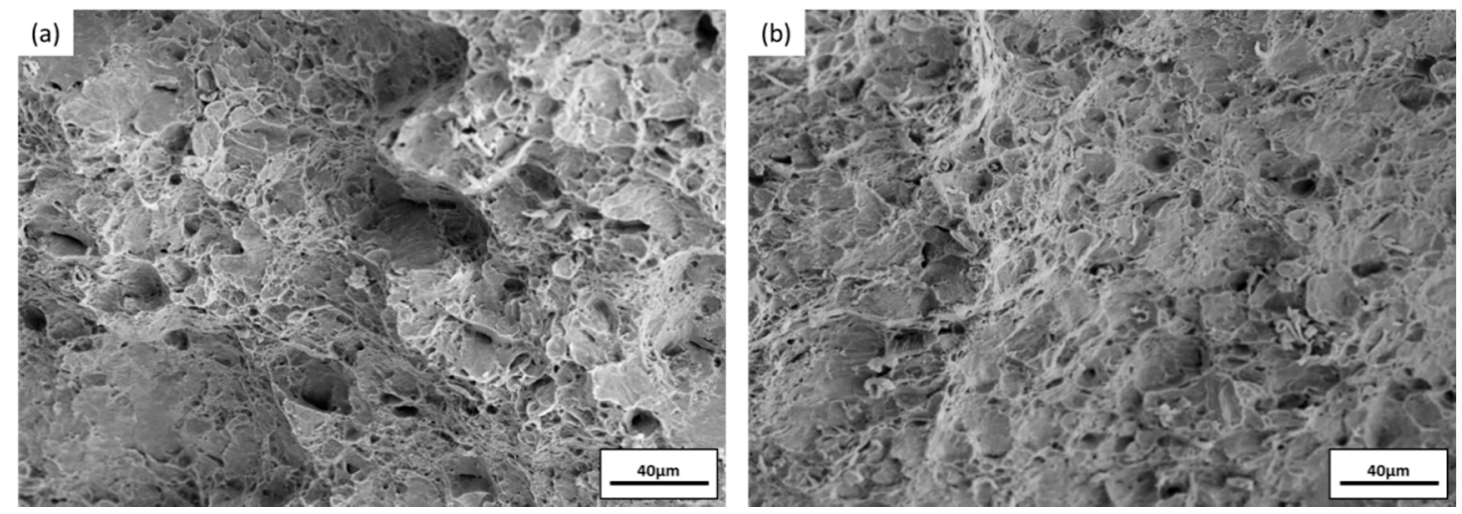

Figure 7. Fracture surface obtained in tensile test: (a) FH and (b) FRH30. 


\subsection{In Vitro Immersion Test}

Figure $8 \mathrm{a}$ depicts the corrosion rates of all of the specimens immersed in $0.9 \mathrm{wt} . \%$ $\mathrm{NaCl}$ solution for 21 days. FRH05 had the lowest corrosion rate, followed by FRH60, FRH30, and FH had the highest corrosion rate. The results indicated that the extruded specimen subjected to rolling, followed by a short period of annealing to reduce the residual stress, had the best corrosion resistance [18]. Figure $8 \mathrm{~b}$ shows the XRD patterns of the FH specimen before and after immersion. The diffraction peak of $\mathrm{Mg}(\mathrm{OH})_{2}$ was observed after immersion. Additionally, some chlorides were found on the surface of specimens. .
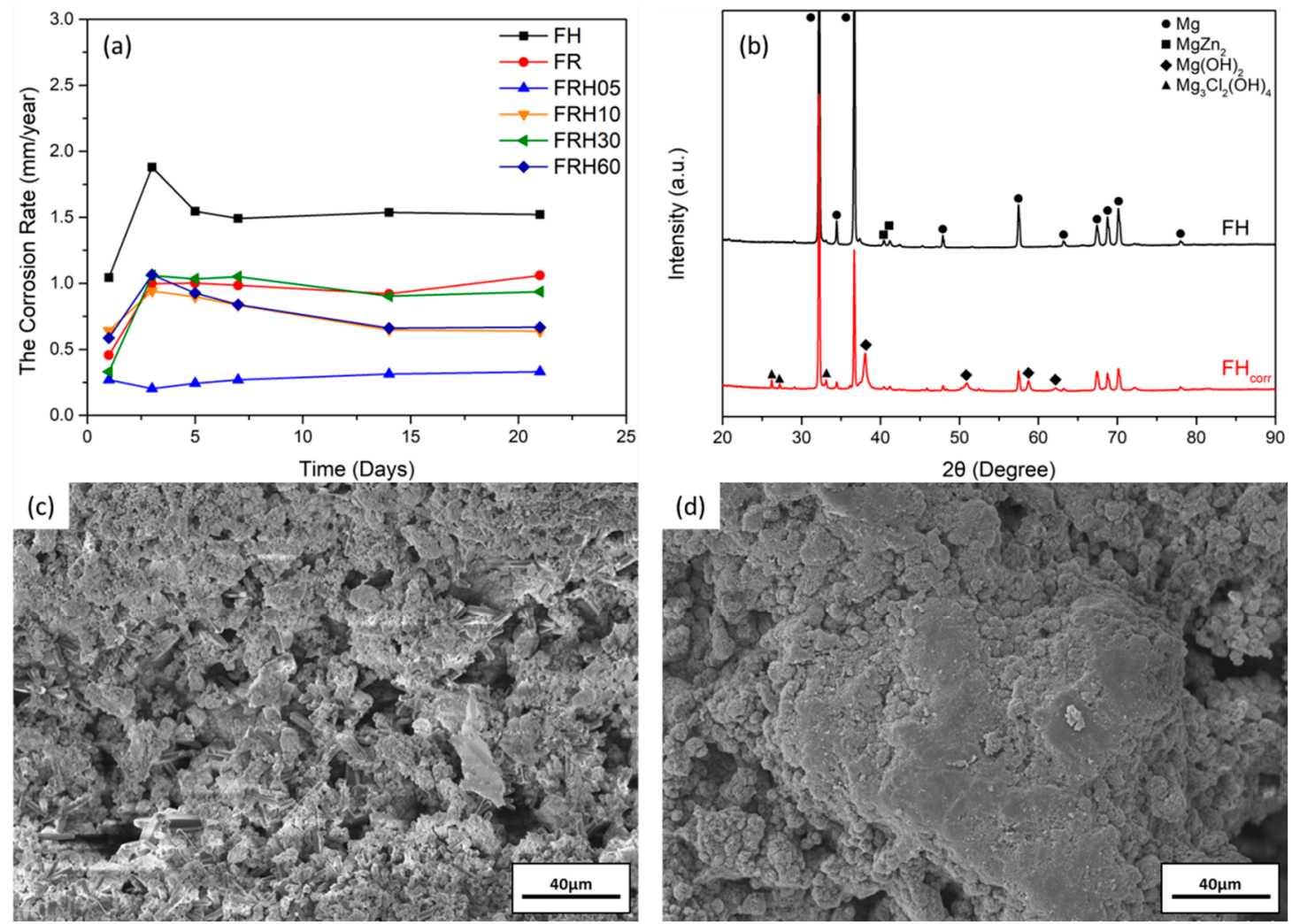

Figure 8. Immersion testing result: (a) Corrosion rate of ZKX500 specimens, (b) XRD patterns before and after immersion testing, (c) FH corroded surface after immersion, and (d) FRH30 after immersion.

Figure $8 \mathrm{c}$ depicts the corrosion surfaces of FH after 21 days of immersion. Cavities were formed on these surfaces due to the potential difference between the $\mathrm{Mg}$ substrate and the second phase, which caused galvanic corrosion [19]. Homogenization heat treatment can partly dissolve the second phase into the matrix, which reduces the potential difference between the substrate and the boundary. However, fine grain and coarse grain could still be found in matrix, leading to severe localized corrosion. The FRH30 specimen exhibited a rolling texture with equiaxed grain structure, except galvanic corrosion, and the pitting effect was weaker on the FRH30 specimen (Figure 8d).

Figure 9 is the EPMA pattern of the FH cross-section after being immersed in $0.9 \mathrm{wt} . \%$ $\mathrm{NaCl}$ solution for 21 days. The surface was covered by corrosion product. Not only $\mathrm{Mg}$ and $\mathrm{Cl}$ element were found in the surface. The corrosion product layer could be divided into two parts, the outer layer shown in yellow line and the inner layer close to matrix shown in red line. The second phase enriched position caused a corrosion pit, which may increase the corrosion rate. The outside layer formed with Ca element could prevent corrosion of Mg substrate. 

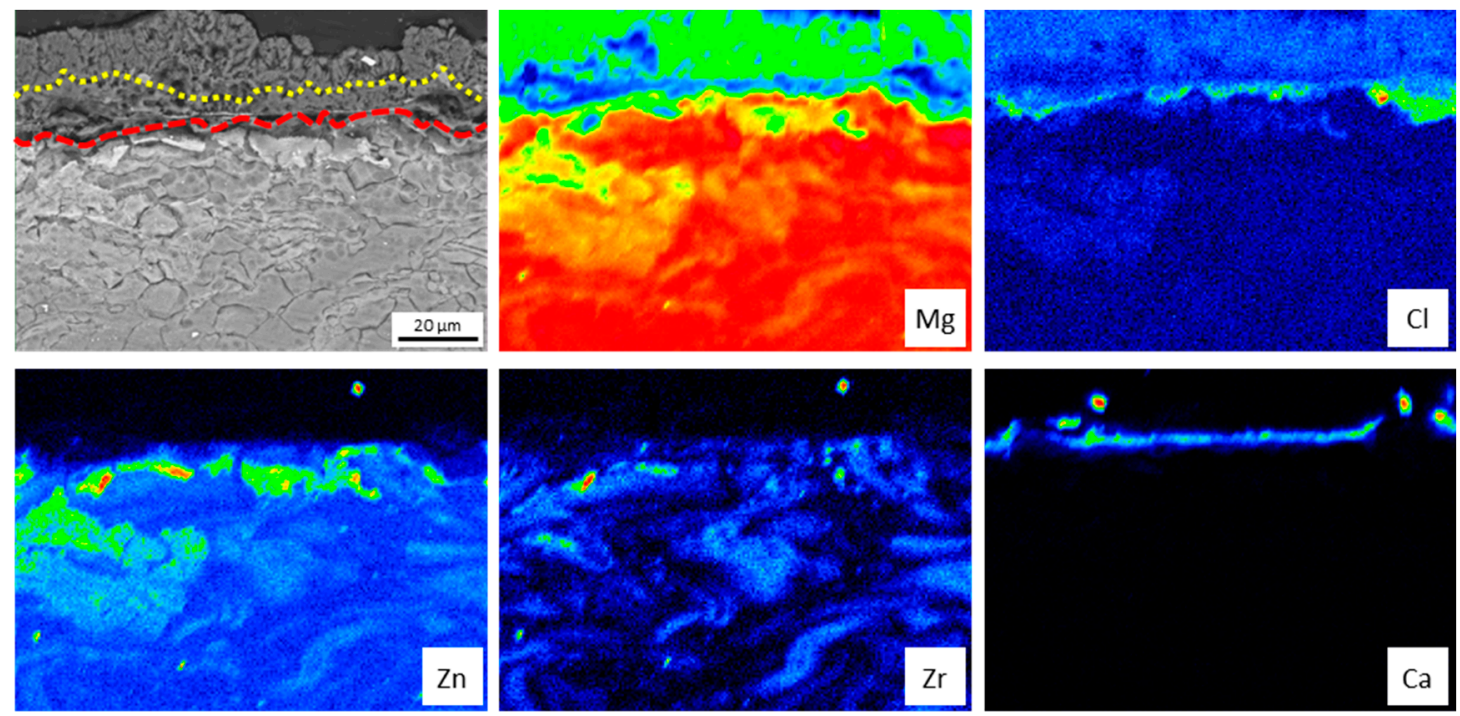

Figure 9. EPMA maping of elements distribution in the cross-section of corroded ZKX500 Mg alloy.

A schematic is shown in Figure 10 to illustrate the corrosion process of ZKX500 Mg alloy in $0.9 \mathrm{wt} . \% \mathrm{NaCl}$ solution. When $\mathrm{Mg}$ was dissolved in water, it formed the passive $\mathrm{Mg}(\mathrm{OH})_{2}$ film deposited on the metal surface, which could prevent corrosion of the $\mathrm{Mg}$ substrate. In the presence of $\mathrm{Cl}^{-}$, the region adjacent to the grain boundary dissolved, and soluble $\mathrm{MgCl}_{2}$ was produced, leading to the destruction of the $\mathrm{Mg}(\mathrm{OH})_{2}$ protective film and the reduction of the corrosion resistance of the $\mathrm{Mg}$ alloy. Hence, in a $\mathrm{NaCl}$ environment, the $\mathrm{Mg}$ alloy has a higher corrosion rate owing to the formation of $\mathrm{MgCl}_{2}$ [20]. The potential different between the $\mathrm{Mg}$ substrate and second phase on the grand boundary caused microgalvanic corrosion. As the corrosion time increased, corrosion pits were formed where the $\mathrm{Mg}$ matrix was adjacent to the second phase particles. As the alloy was dissolved, the concentration of alloying elements (i.e., $\mathrm{Ca}$ ) increased, and when they reached saturation in the $\mathrm{NaCl}$ solution, it precipitated, and, thus, a layer of Ca element was observed.

\subsection{Impact Toughness after Immersion}

Impact toughness of FRH30 was plotted against the days of immersion in Figure 11a, and the cross sections of the specimens were shown in Figure 11b. Initially, the impact toughness was $86 \mathrm{~J} / \mathrm{cm}^{2}$, and, after immersion for 7 days, the value decreased approximately to $60 \mathrm{~J} / \mathrm{cm}^{2}$. However, that the value did not decrease with increasing immersion days, indicated that with controlled corrosion rate, ZKX500 Mg alloy can retain well its mechanical properties. In Figure 11b, the specimen before immersion revealed that there was a larger plastic deformation region than the specimen after immersion. In Figure 11c, the dimples were found in the fracture surface of specimen before immersion, revealing that the specimen had a higher ductility. In contrast, the cleavage step observed in Figure 11d indicated that, after immersion, the ductility decreased. After the immersion process, the surface of the specimen was corroded and micro cracks were formed, which may inhibit cross-slip to non-basal planes and lead to poor impact toughness. 

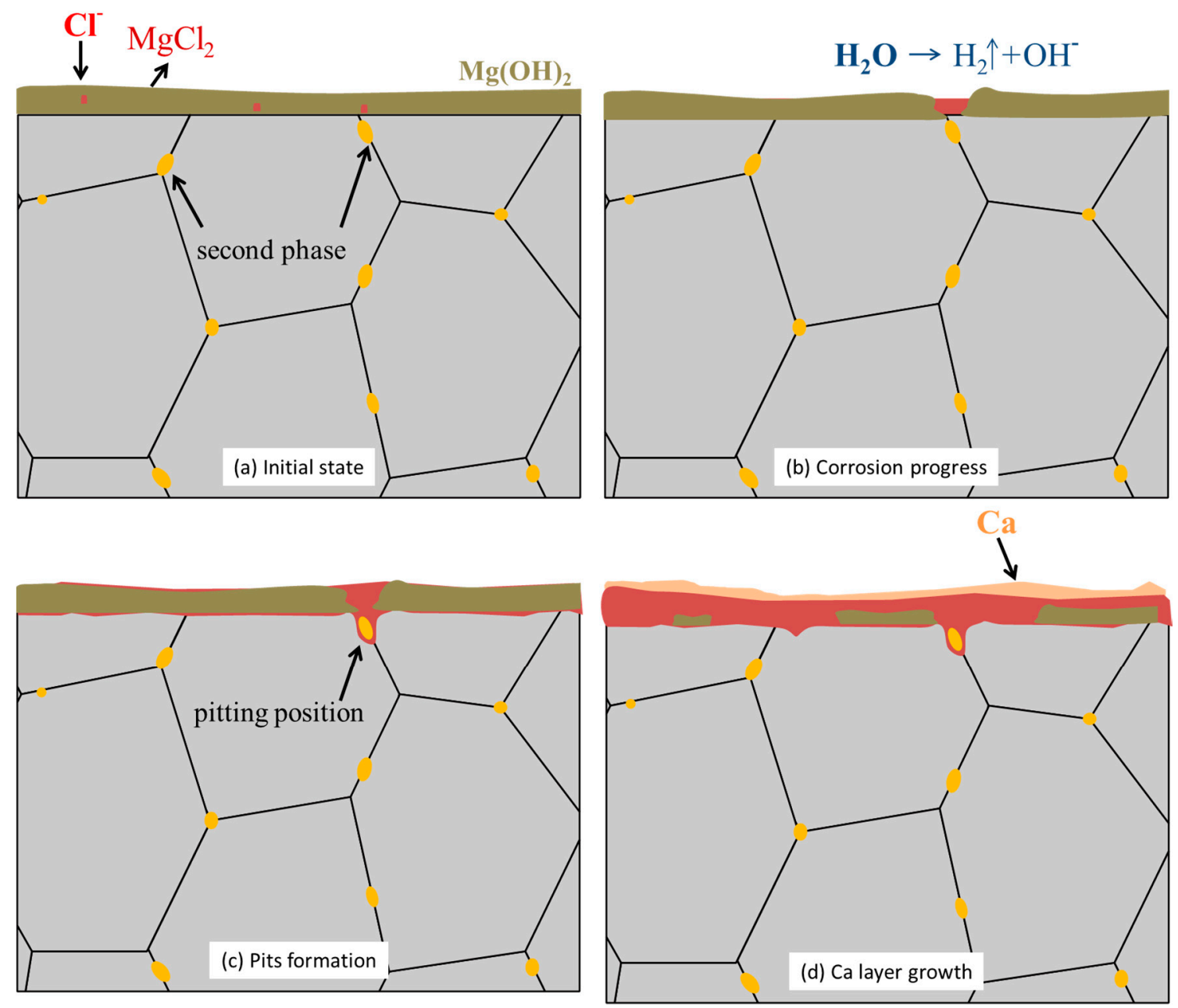

Figure 10. Illustration of corrosion mechanism of ZKX500 Mg alloy.

\subsection{Cytotoxicity Test}

Cytotoxicity is a measurement for evaluating in vitro cell viability. Figure 12 shows the RGR of the extract (FH), negative control (NC), and positive control (PC) incubated for 1,3 , and 5 days. The RGR of the sample decreased after incubation for 3 days because the $\mathrm{Mg}$ degradation released $\mathrm{Mg}^{2+}$ and increased the $\mathrm{pH}$ value. At higher $\mathrm{Mg}^{2+}$ concentrations, the osmotic pressure of the culture media was altered, and the balance between $\mathrm{Mg}^{2+}$ and $\mathrm{Ca}^{2+}$ was disturbed, which had a destructive effect on cells [21]. However, in this study, because the degradation rate was controlled, the RGR values of all of the specimens were $>75 \%$, meaning that the corresponding cytotoxicity levels were Grad 0 or Grad 1 [14]. These results indicated that ZKX500 has no cytotoxicity.

\subsection{Animal Implantation Experiment}

To evaluate the biocompatibility of the ZKX500 Mg alloy, we machined it into a fourhole bone plate, as illustrated in Figure 2c. We implanted the bone plate and four solid bone screws into the radius of the right forelimb of a mini-pig and observed the degradation behaviors of the plate and screw inside the animal. 


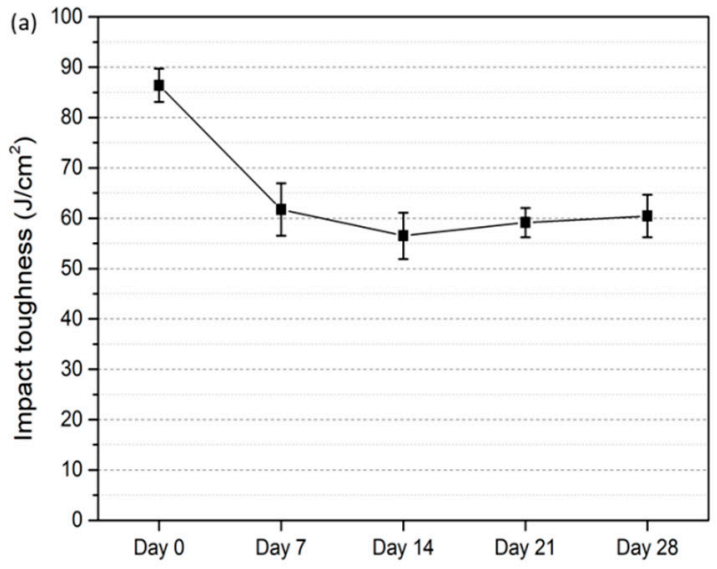

(b)
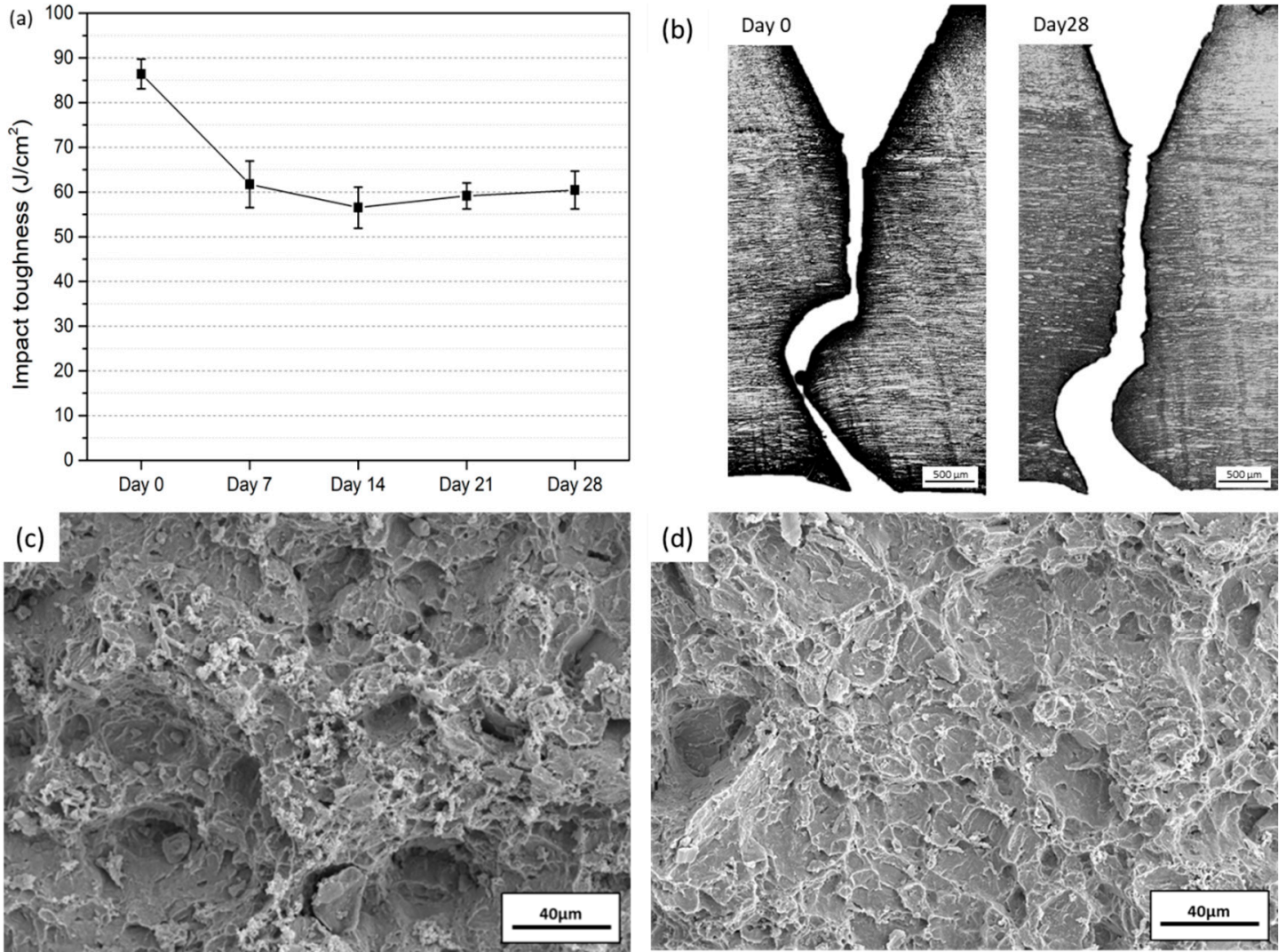

Figure 11. Impact testing: (a) impact toughness after immersion, (b) cross section of impact specimen, (c) fracture surface of before, and (d) after immersion 28 days.

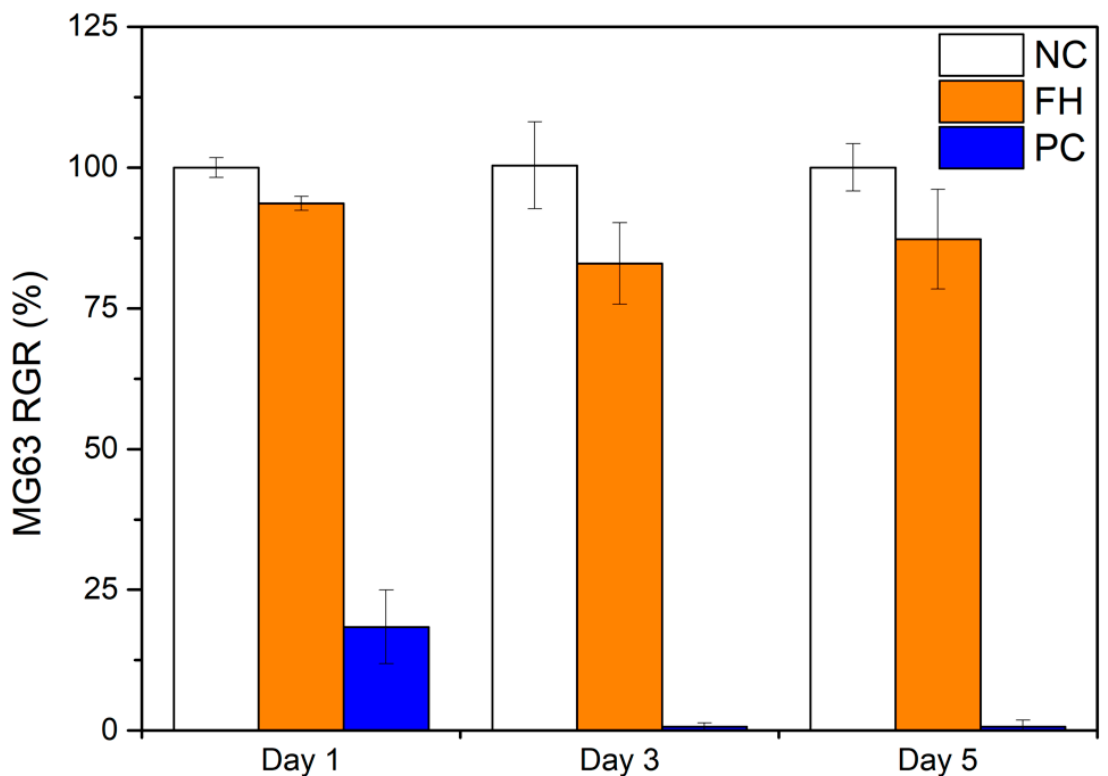

Figure 12. Relative growth rate of MG63 cells for 1, 3, and 5 days (FH, the extract; $\mathrm{NC}$, negative control; PC, positive control).

Figure 13a presents the CT image of the implantation site. Figure 13b shows the CT image right after surgery; in this image, a certain dark area can be observed. After comparative analysis, there was good evidence to show that ZKX500 Mg alloys may have some image interference phenomena. Those dark areas were not gas cavities generated during degradation, but the interference between the bone plate and the tissue. Figure 14 
presents CT images obtained 3 months after surgery. In Figure 14b, new bone tissue (highlighted by the blue arrow) was formed outside the bone plate, which demonstrated that the bone plate can support the injured part effectively and promote the healing of a bone fracture. Due to the degradation, the screw thread was not clearly visible (highlighted by the white arrows in Figure 14c). At 6 months after implantation (Figure 15), only some ZKX500 fragments of the bone screws were found (highlighted by the white arrows in Figure 15d). However, the ZKX500 bone plate retained its shape well; it was degraded only at the edges, and new bone tissue (highlighted by the blue arrows in Figure 15b,d) covered the entire bone plate.

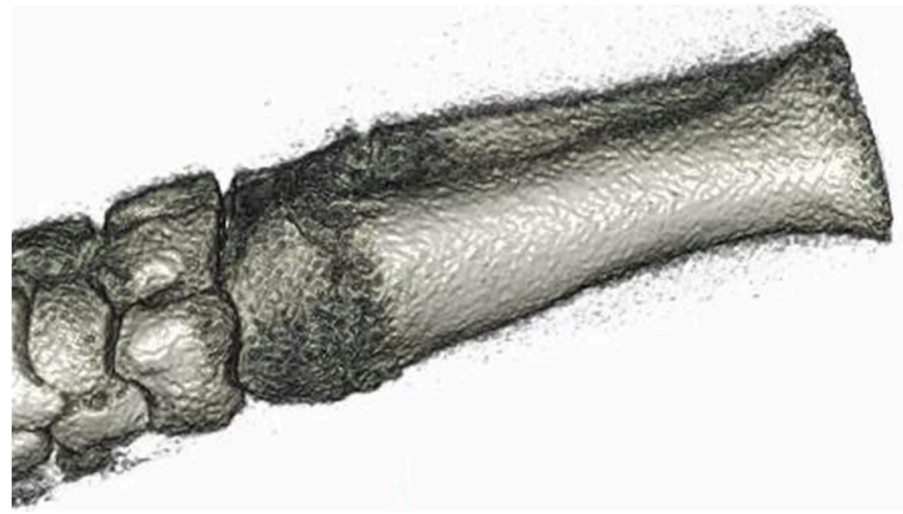

(a)

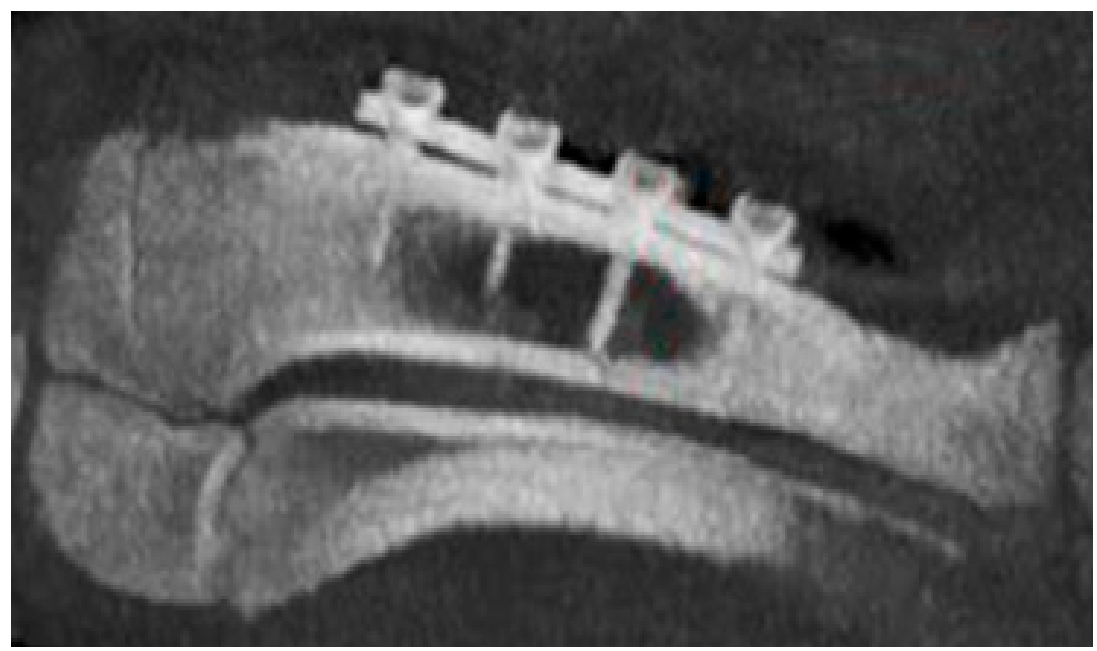

(b)

Figure 13. Micro-CT images: (a) before and (b) after surgery. 


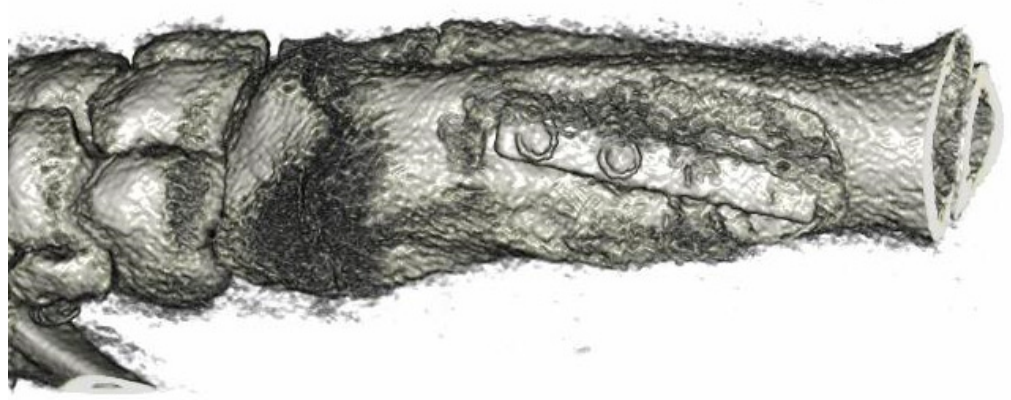

(a)

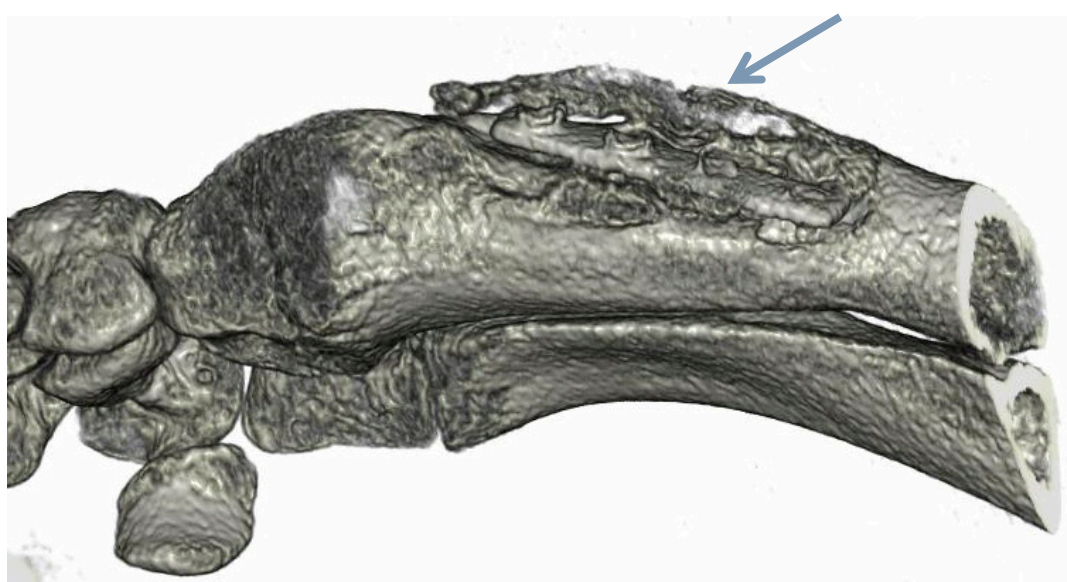

(b)

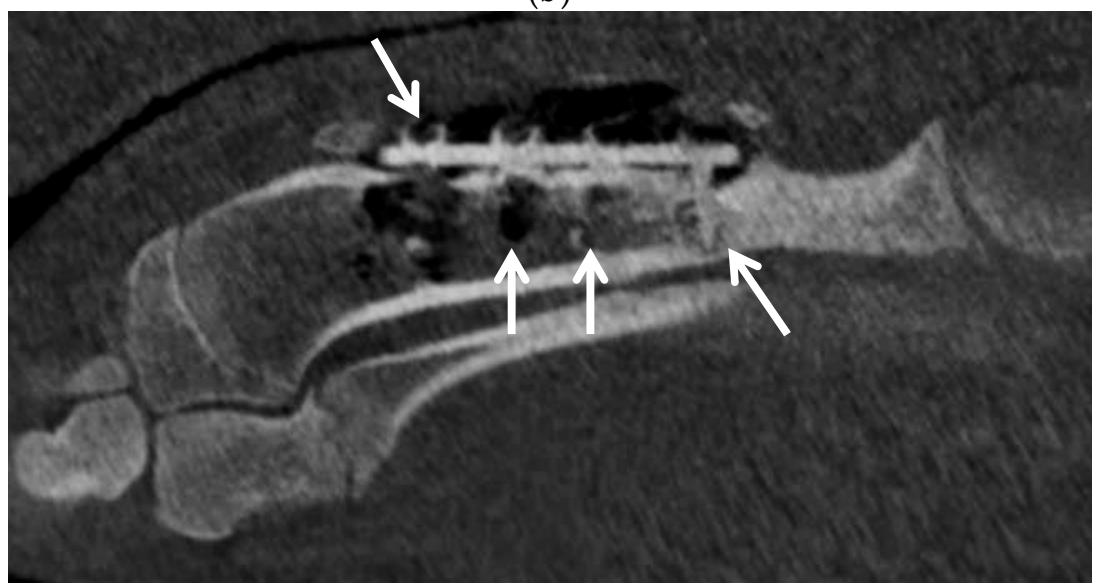

(c)

Figure 14. Micro-CT images recorded 3 months after surgery: (a) 3D reconstruction top view, (b) 3D reconstruction side view, and (c) Micro-CT side view.

The ZKX500 bone screws (not bone plates) were machined directly from extruded material and were not subjected to rolling and annealing, therefore, the $\mathrm{Mg}$ bone screws were found to be degraded completely within 6 months. In this study, the $\mathrm{Mg}$ bone plate was subjected to rolling with a $50 \%$ reduction rate, followed by annealing. Consequently, the the magnesium $\mathrm{Mg}$ alloy bone plate had a uniform structure and textured effect, which effectively reduced its degradation rate while preserving its strength. 


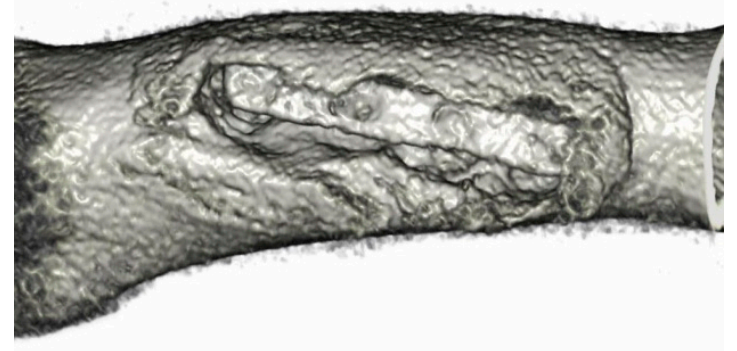

(a)

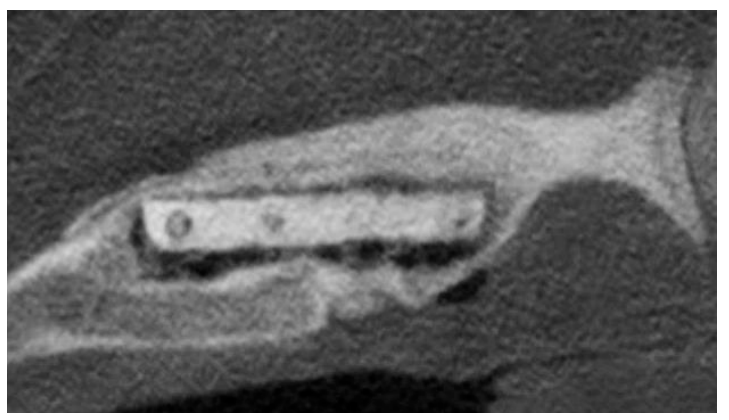

(c)

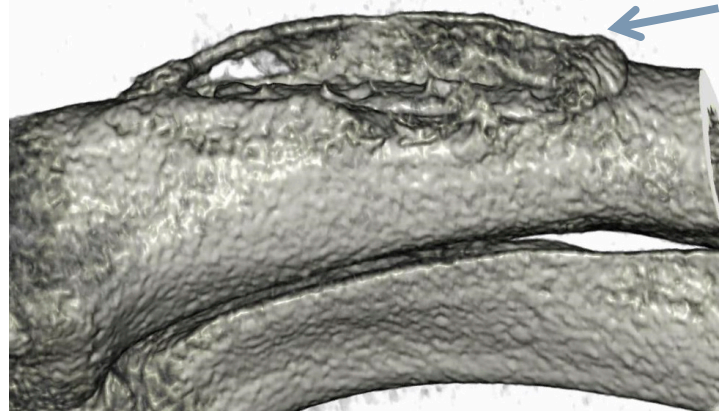

(b)

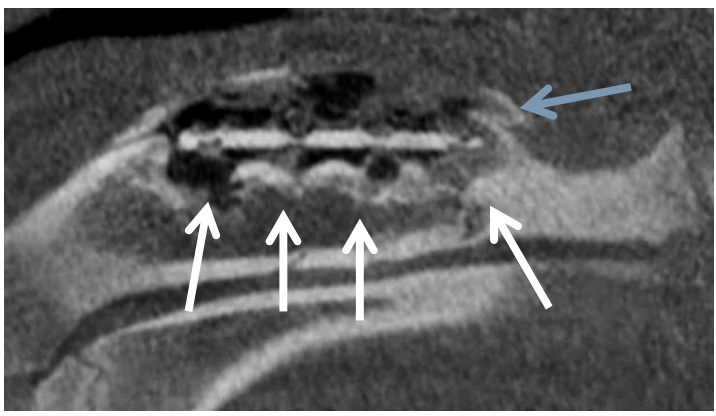

(d)

Figure 15. Micro-CT images recorded 6 months after surgery: (a) 3D reconstruction top view, (b) 3D reconstruction side view, (c) Micro-CT top view, and (d) Micro-CT side view.

\section{Conclusions}

(1) The ZKX500 Mg alloy exhibited good biocompatibility. After rolling and heat treatment, this material had an equiaxed grain structure, which not only preserved its excellent mechanical properties but also reduced its in vitro corrosion rate.

(2) The ZKX500 Mg alloy bone plate exhibited the rolling texture effect. After homogenizing the material and reducing its residual stress, the ZK50 Mg alloy bone plate was used in an animal implantation test. The degradation of the plate was inhibited effectively, and it can assist with the proliferation of new bone.

Author Contributions: Methodology, Y.-T.H.; investigation, Y.-T.H., F.-C.K., K.-L.H., W.-R.S. and C.-Y.L.; data curation, Y.-T.H.; writing-original draft preparation, Y.-T.H.; writing-review and editing, F.-Y.H.; and supervision, F.-Y.H.; funding acquisition, C.-Y.L. All authors have read and agreed to the published version of the manuscript.

Funding: This research received no external funding.

Institutional Review Board Statement: The study was conducted according to the guidelines of the Declaration of Helsinki, and approved by the Institutional Animal Care and Use Committee of NARLabs, Tainan, Taiwan (protocol code: NLAC(TN)-109-M-007, date of approval: 20 July 2020).

Informed Consent Statement: Not applicable.

Data Availability Statement: The data presented in this study are available on request from the corresponding author. The data are not publicly available due to privacy or ethics.

Acknowledgments: The authors are grateful to Taiwan TING SIN Co., Ltd. and the Ministry of Science and Technology of Taiwan (Grant No. MOST 108-2221-E-006-140-MY3) for their financial support.

Conflicts of Interest: The authors declare no conflict of interest.

\section{References}

1. Song, G.-L. Corrosion electrochemistry of magnesium (Mg) and its alloys. Corros. Magnes. Alloy. 2011, 2011, 3-65. [CrossRef] 
2. Han, D.; Zhang, J.; Huang, J.; Lian, Y.; He, G. A review on ignition mechanisms and characteristics of magnesium alloys. J. Magnes. Alloy. 2020, 8, 329-344. [CrossRef]

3. Chen, Y.; Xu, Z.; Smith, C.; Sankar, J. Recent advances on the development of magnesium alloys for biodegradable implants. Acta Biomater. 2014, 10, 4561-4573. [CrossRef] [PubMed]

4. Bohlen, J.; Wendt, J.; Nienaber, M.; Kainer, K.U.; Stutz, L.; Letzig, D. Calcium and zirconium as texture modifiers during rolling and annealing of magnesium-zinc alloys. Mater. Charact. 2015, 101, 144-152. [CrossRef]

5. Pawar, S.; Slater, T.; Burnett, T.; Zhou, X.; Scamans, G.; Fan, Z.; Thompson, G.; Withers, P. Crystallographic effects on the corrosion of twin roll cast AZ31 Mg alloy sheet. Acta Mater. 2017, 133, 90-99. [CrossRef]

6. Zhu, S.; Yan, H.; Chen, J.; Wu, Y.; Liu, J.; Tian, J. Effect of twinning and dynamic recrystallization on the high strain rate rolling process. Scr. Mater. 2010, 63, 985-988. [CrossRef]

7. Miao, Q.; Hu, L.; Wang, X.; Wang, E. Grain growth kinetics of a fine-grained AZ31 magnesium alloy produced by hot rolling. J. Alloy. Compd. 2010, 493, 87-90. [CrossRef]

8. Zhang, S.; Bi, Y.; Li, J.; Wang, Z.; Yan, J.; Song, J.; Sheng, H.; Guo, H.; Li, Y. Biodegradation behavior of magnesium and ZK60 alloy in artificial urine and rat models. Bioact. Mater. 2017, 2, 53-62. [CrossRef] [PubMed]

9. Chen, Y.-T.; Hung, F.-Y.; Lin, Y.-L.; Lin, C.-Y. Biodegradation ZK50 magnesium alloy compression screws: Mechanical properties, biodegradable characteristics and implant test. J. Orthop. Sci. 2020, 25, 1107-1115. [CrossRef]

10. Moradnezhad, S.; Razaghian, A.; Taghiabadi, R.; Abedi, H.R.; Salandari-Rabori, A.; Emamy, M. Effect of Ca additions on evolved microstructures and subsequent mechanical properties of a cast and hot-extruded $\mathrm{Mg}-\mathrm{Zn}-\mathrm{Zr}$ magnesium alloy. Int. J. Adv. Manuf. Technol. 2019, 104, 4265-4275. [CrossRef]

11. ASTM International. Standard Practice for Laboratory Immersion Corrosion Testing of Metals; ASTM-G31-72; ASTM: West Conshohocken, PA, USA, 2004.

12. Liu, L.; Gebresellasie, K.; Collins, B.; Zhang, H.; Xu, Z.; Sankar, J.; Lee, Y.-C.; Yun, Y. Degradation Rates of Pure Zinc, Mag-nesium, and Magnesium Alloys Measured by Volume Loss, Mass Loss, and Hydrogen Evolution. Appl. Sci. 2018, 8, 1459. [CrossRef]

13. Walker, J.; Shadanbaz, S.; Kirkland, N.T.; Stace, E.; Woodfield, T.; Staiger, M.P.; Dias, G.J. Magnesium alloys: Predicting in vivo corrosion with in vitro immersion testing. J. Biomed. Mater. Res. Part B Appl. Biomater. 2012, 100B, 1134-1141. [CrossRef] [PubMed]

14. ISO E. 10993-5: Biological Evaluation of Medical Devices- Part 5: Tests for In Vitro Cytotoxicity. Available online: https: //webstore.ansi.org/preview-pages/BSI/preview_30356171.pdf (accessed on 1 November 2021).

15. Klein-Júnior, C.A.; Zimmer, R.; Hentschke, G.S.; Machado, D.C.; Dos Santos, R.B.; Reston, E.G. Effect of heat treatment on cyto-toxicity of self-adhesive resin cements: Cell viability analysis. Eur. J. Dent. 2018, 12, 281-286. [PubMed]

16. Imwinkelried, T.; Beck, S.; Schaller, B. Pre-clinical testing of human size magnesium implants in miniature pigs: Implant degradation and bone fracture healing at multiple implantation sites. Mater. Sci. Eng. C 2020, 108, 110389. [CrossRef] [PubMed]

17. Mostaed, E.; Hashempour, M.; Fabrizi, A.; Dellasega, D.; Bestetti, M.; Bonollo, F.; Vedani, M. Microstructure, texture evolution, mechanical properties and corrosion behavior of ECAP processed ZK60 magnesium alloy for biodegradable applications. J. Mech. Behav. Biomed. Mater. 2014, 37, 307-322. [CrossRef] [PubMed]

18. Wang, H.; Estrin, Y.; Zúberová, Z. Bio-corrosion of a magnesium alloy with different processing histories. Mater. Lett. 2008, 62, 2476-2479. [CrossRef]

19. Cai, S.; Lei, T.; Li, N.; Feng, F. Effects of Zn on microstructure, mechanical properties and corrosion behavior of Mg-Zn alloys. Mater. Sci. Eng. C 2012, 32, 2570-2577. [CrossRef]

20. Bakhsheshi-Rad, H.R.; Hamzah, E.; Medraj, M.; Idris, M.H.; Lotfabadi, A.F.; Daroonparvar, M.; Yajid, M.A.M. Effect of heat treat-ment on the microstructure and corrosion behaviour of Mg-Zn alloys. Mater. Corros. 2014, 65, 999-1006. [CrossRef]

21. Zhen, Z.; Liu, X.; Huang, T.; Xi, T.; Zheng, Y. Hemolysis and cytotoxicity mechanisms of biodegradable magnesium and its alloys. Mater. Sci. Eng. C 2015, 46, 202-206. [CrossRef] [PubMed] 